\title{
Caracterização da demanda potencial por atividades de aventura
}

\author{
Giuliano Gomes de Assis Pimentel ${ }^{1}$ \\ Caroline Fama Saito ${ }^{2}$ \\ ${ }^{1}$ Universidade Estadual de Maringá, PR, Brasil \\ ${ }^{2}$ CESUMAR - Centro Universitário de Maringá, PR, Brasil
}

Resumo: O estudo abordou sujeitos da região metropolitana de Maringá, Paraná, com o objetivo de caracterizar a demanda potencial e o interesse pela prática de atividades de aventura. É significativo o não-interesse, embora a maior parte da população tenha noção de quais são as principais atividades de aventura. No campo esportivo, pára-quedismo, surf e vôo livre são os mais citados e desejados, evidenciando uma afinidade entre conhecer e interesse. Citam como as características mais marcantes dos praticantes de esportes de aventura: possuir recursos econômicos; estar entediado com a rotina; e ter condicionamento físico. Ao imaginar essas características como realidade, as pessoas comuns tendem à auto-exclusão na prática das aventuras de lazer.

Palavras-chave: Atividades de lazer. Estilo de vida. Natureza. Qualidade de vida.

\section{Characterization of the potential demand for activities of adventure}

\begin{abstract}
This study approached people resident en the metropolitan region of Maringá, Paraná, with the objective to establish the profile of potential necessity and the interest for practice of adventure activities. It is significant the no-interest for the practice, although the major part of the population have a notion about which are the main adventure activities. Parachute, surf, hang glide are the most quoted and desired. The more important characteristics of people who practice sports are, according to the sample: have financial conditions, be tired with the routine and have physical conditions to practice. In agreement these characteristics as reality, common people tend to self-exclusion in the practice of adventure of leisure.
\end{abstract}

Key Words: Leisure activities. Life style. Nature. Quality of life.

\section{Introdução}

O crescimento da oferta esportiva e turística de atividades de aventura, aliado ao interesse que o tema desperta na mídia e, mais tardiamente, na ciência, pode fornecer uma interpretação de que essas práticas sejam amplamente conhecidas e desejadas entre as pessoas comuns do cotidiano. Mas, será realmente? Este estudo buscou, entre as pessoas comuns do cotidiano, o conhecimento e o interesse sobre aventura.

Para tanto, se parte do entendimento mais abrangente de "atividades de aventura" como toda experiência invulgar de risco (real ou imaginado) e incerteza, podendo ser procurada em diferentes ambientes, os quais estão associados a novas descobertas. Logo, a aventura pode estar presente tanto em um acampamento quanto em um mergulho submarino. Entretanto, o mais recorrente é associação da aventura com natureza, esporte e turismo.

Conforme Betrán (2003), a proximidade da aventura com a natureza se dá em função da imprevisibilidade do meio. Além disso, nas sociedades ditas pós-industriais se alimenta um retorno hedonista ao ambiente natural, especialmente entre a juventude. Tal fenômeno dá a impressão de ainda experimentar crescimento, tanto no número de praticantes quanto no surgimento de novas modalidades esportivas, as quais são captadas pelos operadores de turismo como estratégias de atração nas viagens à natureza.

Em acréscimo, no Ocidente as atividades de aventura passaram por um processo de submissão à lógica do mercado, especialmente a partir da década de 1980, quando áreas nãourbanizadas passaram a ser incorporadas a destinos turísticos juntamente com empreendimentos em diversas modalidades. A partir desse período, a relação entre contato com a natureza, o tempo livre e os cuidados com a saúde se tornaram sinônimos de distinção social e qualidade de vida, para mais tarde alcançarem sua expansão atual (AMARAL, 2005).

Segundo Swarbrooke et al. (2003), o turismo de aventura, especialmente na região Amazônica, é, junto ao Carnaval, um dos dois pólos principais 
de atração internacional do Brasil. Em termos mundiais, nos últimos anos, a taxa de crescimento nesse segmento tem sido consideravelmente mais alta que a de outras formas de turismo.

Acompanhando o desenvolvimento das atividades de aventura pode-se também observar o crescimento e as tendências para o mercado de aventura como uma demanda global. No Brasil, as pessoas que procuram as atividades de aventura são caracterizadas como praticantes com idades entre 25-50 anos, bem estabelecidos financeira e profissionalmente. A motivação desse tipo de indivíduo por atividades de aventura na natureza, de acordo com Amaral (2005, p.235), tem relação com seu modo de vida empreendedor e o fato de que "o turismo de aventura seduz pelo desejo das pessoas de colocar à prova suas emoções e desafiar os próprios limites". De modo complementar, estaria relacionado ao bem-estar por pressupor a "troca de uma vida sedentária pela prática de atividades que promovem a saúde".

Em consequência, existe certa dificuldade em diferenciar o esporte do turismo no ramo da aventura, pois ambos estão associados a sensações similares. Porém, o esporte de aventura denota envolver maior autonomia do praticante sobre a segurança e, em última instância, sua moral ser influenciada pela codificação esportiva, podendo ser conceituado como "conjunto de práticas esportivas formais e não formais, vivenciadas em interação com a natureza, a partir de sensações e de emoções, sob condições de incerteza em relação ao meio e de risco, realizadas em ambientes naturais (ar, água, gelo e terra, sob controle das condições de uso de equipamentos" (COSTA; MARINHO; PASSOS, 2007, p. 108).

Embora pareça que tais atividades estejam em fase de expansão, sendo procuradas por pessoas de diferentes grupos, não existem muitos estudos que enfoquem o perfil dos praticantes e de suas motivações. Esses dados, em geral, são produzidos pelo empresariado do setor de turismo de aventura, o qual se restringe aos grupos que interessam economicamente ao mercado. Desse modo, as representações das pessoas do cotidiano, praticantes ou não, é um aspecto ainda mais desconhecido. O que a população em geral pensa sobre as atividades de aventura? Quais são mais conhecidas? O que chama atenção das pessoas referente a esse universo?

Partindo dessa lacuna no conhecimento, realizamos um trabalho de mapeamento, desenvolvimento de modo exploratório na região metropolitana de Maringá-Paraná. Nele identificamos qual o entendimento que a população em geral tem das atividades de aventura e, dentro do conhecimento dos praticantes, como se caracteriza essa prática.

\section{Materiais e Métodos}

Visando abranger uma quantidade grande de sujeitos, e que os mesmos pudessem ser selecionados aleatoriamente pelo critério de acessibilidade, o estudo adotou como instrumento de trabalho a entrevista estruturada e as pessoas foram abordadas em locais de circulação pública (na rua, em pontos de ônibus e rodoviárias). As mesmas não tiveram acesso ao instrumento até que as perguntas fossem respondidas. Por essa característica, o survey obteve as respostas espontâneas, ou seja, aquilo que o indivíduo lembra e pensa de forma automática. O instrumental do tipo survey, de acordo com Thomas e Nelson (2002), é uma técnica de pesquisa descritiva que procura determinar práticas presentes ou opiniões de uma população específica; podendo tomar a forma de um questionário ou entrevista, como foi utilizado no presente estudo.

A amostra tem perfil diversificado, dado ter sido feita com seleção aleatória e em diferentes cidades e bairros. Foram inquiridas 207 pessoas com idades variantes entre 10 e 78 (idade modal 18 anos e média 34 anos), residentes em três cidades na região metropolitana de Maringá, norte do Paraná. Maringá é a terceira cidade do Paraná, com população de 324.397 habitantes e Índice de Desenvolvimento Humano (IDH) de 0,841 . A economia transita em torno da agricultura em escala industrial. Como pólo regional de educação, possui um número de 16.371 alunos matriculados no ensino médio e 28.471 no ensino superior. As outras duas cidades em que ocorreu coleta foram Sarandi (78.643 habitantes, IDH de 0,768) e Paiçandu (população de 33.403 habitantes, IDH de 0,746).

Uma vez coletados os dados, estes foram tabulados e, depois, estabelecidas correlações das respostas - por meio de triangulação - com os eixos cidade/região; faixa etária, profissão e 
escolaridade. Um limite foi não terem sido observadas as variáveis gênero e renda. Embora esse tipo de procedimento, impregnado pela lógica empírico-analítica, não permita imersão sobre o objeto, é de utilidade para fornecer panoramas e novas problemáticas ao desenvolvimento de estudos qualitativamente densos.

Lahire (2006), ao tratar da necessidade em compreender o alcance desse tipo de pesquisa na sociologia, lembra que, de fato, o cruzamento de variáveis como nível de formação do entrevistado ou categoria socioprofissional com os diferentes indicadores de consumos culturais (preferência por um gênero, freqüência a um tipo de programa cultural, etc.), permite chegar-se à probabilidade desigual de acesso a certa categoria de bens. Com isso, no desdobramento de tais pesquisas é possível estabelecer correspondência estatística entre as hierarquias das práticas e hierarquia social dos consumidores. Mas, para o presente texto, o estudo exploratório apenas ousou em trazer provocações, dando indícios de relações que devem ser refutadas ou corroboradas em estudos com um $n$ mais significativo e com representatividade regional ou nacional.

A interpretação buscou o conhecimento que a população local compartilha sobre as atividades de aventura. Toma-se, portanto, as representações sociais como canal de partida para evidenciar a demanda reprimida e a prática efetiva. Por outro lado, o aporte teórico e análise do contexto permitiram, na análise do material, encontrar as contradições, interditos e obscuridades do discurso, uma vez que este não é transparente, ou seja, não corresponde à realidade concreta, mas, sim, a uma interpretação dela (MINAYO, 1999; SPINK, 1995).

Determinados dados que se manifestaram não-explicativos e, pelo contrário, invitaram novas dúvidas, geraram aprofundamentos a partir de outro instrumental de coleta (entrevista semiestruturada) e aplicado de forma qualitativa entre sub-amostragem específica, isto é, sujeitos qualificados para fornecerem elucidações acerca do que o dado quantitativo apenas insinuou.

Fizeram parte desse segundo momento comerciantes da área, especialistas em segurança pública e alguns praticantes de skate. Esse grupo gerou um desdobramento a partir dos primeiros dados porque os resultados do survey apontaram para pouco interesse pelo skate em confronto com o significativo número de praticantes. A expectativa foi obter características dos sujeitos que compõem este campo consumidor, a fim de aprofundar o conhecimento sobre esse grupo, tendo como maior dificuldade o tempo dos sujeitos para conceder as entrevistas.

O resultado é apresentado em dois tópicos, tendo o primeiro privilegiado considerações aqui sempre provisórias por mais que incisivas pertinentes ao universo representacional dos não-praticantes. No segundo momento, são extraídos e discutidos dados sobre a demanda real e reprimida pelas atividades de aventura, sejam elas urbanas ou na natureza.

\section{Preferências e rejeições}

Entre a amostra, quando indagados sobre quais atividades de aventura conheciam, apenas 03,3\% respondeu não conhecer nenhuma. Ao todo, foram lembradas 40 práticas corporais, dentre as quais um número pequeno de citações chamou atenção para vieses que o entendimento de aventura pode ter: confronto (lutas como boxe, karatê e judô), competições eqüestres (vaquejada, hipismo) e ações ilícitas (racha de carros).

As atividades de aventura mais conhecidas foram as 'esportivizadas': Pára-quedismo foi lembrado por $58,93 \%$ das pessoas. Na seqüência tem-se surf $(53,14 \%)$, vôo-livre $(52,17 \%)$, rapel $(50,72 \%)$, skate $(50,72 \%)$, trekking $(42,51 \%)$, motocross $(42,02 \%)$, balonismo $(40,57 \%)$, rodeio $(39,61 \%)$ e rafting $(32,85 \%)$. Em média cada pessoa recordou-se de 6,32 atividades. Interessante notar que a menção à aventura não implicou em delimitação às ações motrizes na natureza, mas compreendeu as diferentes interfaces do ser humano com o meio ambiente, inclusive o urbano.

O rodeio foi a atividade mais incomum entre as dez atividades de aventura mais lembradas. Infere-se que essa resposta esteja relacionada ao contexto de interior do Paraná, onde o rodeio é um esporte de risco conhecido por meios das festas de peão recorrentes em todo o Norte do Paraná. Também neste sentido, o balonismo foi lembrado por $40,57 \%$ dos inquiridos, o que pode ter sido influenciado pelo festival anual desse esporte na cidade. A ausência de morros e florestas extensas favorece o vôo de balão nessa 
região em termos de segurança e dirigibilidade. Por isso, vale supor que as respostas variarão se o instrumento for aplicado em outra região. O entorno sociocultural e físico apresenta-se como uma variável importante na quantidade e qualidade das respostas sobre o que uma determinada população concebe por atividade de aventura. Outro aspecto importante estaria ligado à exposição desigual que cada qual possui na mídia. Quanto mais divulgada, maior é a possibilidade de ser lembrada espontaneamente.

Por fim, é importante considerar o peso simbólico e estético de cada atividade, no sentido de, por exemplo, possuir plasticidade ou ser mais inacessível ou perigosa tornar algo mais emblemático da aventura no imaginário coletivo. A dimensão simbólica relativa ao "gosto" deve ser considerada sobremaneira em relação às experiências desejadas. A ordem inicial de interesse se manteve com pára-quedismo (18,84\%), surf $(12,07 \%)$, vôo-livre $(11,59 \%)$ e rapel $(9,17 \%)$; sendo seguidos por balonismo $(8,69 \%)$ e montanhismo $(5,31 \%)$.

Vale ressaltar que nem tudo que é conhecido foi desejado pelos sujeitos. Noutras palavras, no campo das representações, é identificável que algumas práticas, apesar da exposição que recebem e de serem conhecidas, não geraram demanda. Quando questionados sobre quais práticas demandariam interesse, houve sinalização pela prática de 02 atividades de aventura / per capta contrastando com 06 atividades em média conhecidas.

O rodeio pode exemplificar esse movimento de haver manifestações admitidas como atividade de aventura, mas que não atraem o interesse pela prática. Como parte do estilo de vida country, o rodeio não está inserido no circuito turístico de aventura e nem possui "escolinhas" especializadas, o que pode ser um reflexo da baixa demanda. Mas, sobretudo, o rodeio não se enquadra ao padrão hedonista de interação com a natureza. Conforme o tipo-ideal de Betrán (2003) para as atividades físicas de aventura na natureza, as pessoas buscam prazer em um desafio pacífico e controlado com a natureza (com risco, mas sem perigos). Entretanto, o rodeio é divulgado na mídia mais pelos acidentes que pelo prazer proporcionado por sua vivência. Uma vez sendo o hedonismo um dos fatores intrinsecamente associados ao crescimento das atividades de aventura, o rodeio está longe de atrair praticantes recreativos.

Observou-se também que o skate apesar de constar entre os mais conhecidos, não está presente na listagem dos mais desejados para a prática. O que teria levado a tal resultado? Afinal, o skate é um 'esporte radical', com risco controlado, praticado por jovens e com presença de tecnologia, mas de baixo custo. A esse respeito, o estudo foi acrescido de uma parte qualitativa demarcada por 11 entrevistas a atores diversos (força policial, comércio especializado, praticantes).

A questão da marginalidade do esporte, conseqüência de desconhecimento e preconceito é justificativa recorrente, especialmente por uma suposta associação do skate com drogas e vandalismo. Conforme um skatista, 18 anos, diz:

As pessoas têm muita falta de informação. Porque o esporte que eu pratico muitas pessoas desconhecem. E têm várias outras modalidades [ ]...e se a pessoa procurar conhecer mais, e procurar conhecer os praticantes, os atletas, elas podem mudar essa opinião. (Sujeito B)

Outro fator que poderia colaborar para estes resultados diz respeito às características da maioria destes grupos skatistas, como usar roupas largas, que fogem dos padrões da moda esportiva. Constatou-se também, através de entrevistas com policiais da Polícia Militar e Civil, que não existe uma diretiva para abordar esse grupo como suspeitos potenciais. Todavia, devido a pequenos grupos de vandalismo classificaremse como skatistas de ruas, os praticantes em geral têm sua imagem relacionada a consumo de drogas e delitos contra o patrimônio.

Porém, considerando as desigualdades sociais no país e como os jovens encontram-se mais vulneráveis, a pressão sobre os mesmos é algo generalizado, havendo reações insubordinadas e esporádicas à falta de acesso a direitos constitucionais, a exemplo do esporte e lazer. Deste modo, a marginalidade, no sentido de estar à margem, é algo constitutivo ao jovem e às suas práticas na atual etapa da modernidade.

Este fator nos possibilitaria ainda a justificativa de respostas associadas a sair da rotina $(18,26 \%)$. O entendimento do lazer e da aventura como válvula de escape ao cinza diário esteve presente em diferentes faixas etárias e modalidades de aventura. Quando analisamos a tendência contemporânea da sociedade 
capitalista, observamos que as pessoas estão heterocondicionadas ao seu trabalho, seguindo normas e regras alheias à sua autodeterminação. Assim, considerando essa contradição inefável entre a necessidade de adequação social e o desejo pela aventura que o homem carrega dentro de si, estamos interpretando que o franco desenvolvimento das práticas esportivas de aventura pode relacionar-se ao "descontrole controlado" da aventura no lazer.

Nesse sentido, nos aproximamos da teses de Norbert Elias sobre as atividades de risco controlado se constituírem numa forma socialmente aceita pela sociedade para a descarga emocional das tensões do cotidiano. Mesmo sendo vistas como crítica e alternativa ao esporte, as atividades de aventura, analogamente às práticas esportivas, preenchem importantes funções sociais referentes à supressão da necessidade de atividades físicas e a compensação do estresse provocado pela rotina de trabalho, funcionando como um espaço de "descontrole-controlado". (GEBARA, 2000).

A própria noção de quem seja o aventureiro recreativo, reforça a leitura supra mencionada, bem como abre perspectivas de análise. Segundo os sujeitos, as características mais marcantes dos praticantes de esportes de aventura são: possuir recursos econômicos (17,01\%), condicionamento físico $(14,93 \%)$, estar entediado com a rotina $(15,62 \%)$, ser turista, estar em férias $(12,84 \%)$, personalidade desequilibrada $(9,72 \%)$ e gostar do contato com a natureza (3,12\%).

Se forem enfocados os respondentes, vê-se que a associação das práticas de aventura com a relação homem-natureza é fraca nas representações sociais. Isso contrariaria outros estudos que mostram como a aventura esportiva evoca a natureza. Porém, em geral, a exemplo do trabalho de Dias, Alves Júnior (2007), na cidade do Rio de Janeiro, as pesquisas que apontaram para a relação aventura e natureza analisaram participantes reais e em locais privilegiados com recursos como mar, montanha, florestas e cachoeiras. Já, este estudo, englobou atores nãopraticantes e em uma região com poucos atrativos naturais. Logo, vale suspeitar que, no senso-comum de quem está fora do 'meio' de praticantes, não existe uma relação a priori entre ser aventureiro e a busca pela natureza.
Por outro lado, aventura e fase da vida foi uma associação forte, pois $23,1 \%$ das pessoas abordadas relacionam as atividades de aventura a dimensões privilegiadas, com a da juventude, em respostas do tipo possuir tempo livre e, principalmente, "condicionamento físico". Interessante notar que a média e mediana etária de quem se pronunciou a respeito do condicionamento coincide com 32 anos, enquanto aqueles que acreditam serem as atividades de aventura algo para pessoas não ocupadas com o mundo do trabalho (desocupados) estão na faixa dos 41 anos.

Parece haver correlação entre interpretação e a faixa etária e, também, a vivência dessas práticas. O grupo adulto mais novo teve mais experiência de aventura, mas ressente-se da pouca resistência corporal. Já aqueles que associam a prática à disponibilidade de tempo livre (ou até ocioso) se encontram na idade desvio padrão dos praticantes (logo, poucos vivenciaram alguma aventura) apresentando certa visão estereotipada do praticante.

Além da idade, há relação da escolaridade com a aceitação dessas práticas. Entre os que $(\mathrm{N}=21,9,25 \%$ da amostra) consideram a aventura de lazer, algo comum a pessoas desequilibradas, coisa de maluco, $76,1 \%$ são pessoas com instrução abaixo de nível superior e $52,38 \%$ possuem idade acima da média da amostra (34 anos). Entre os que ( $\mathrm{N}=102,44,9 \%)$ consideram benéfico à qualidade de vida, $63,7 \%$ são pessoas com instrução abaixo de nível superior e $57,8 \%$ possuem idade abaixo da média da amostra (34 anos). Portanto, há mais escolaridade superior e menor idade entre sujeitos com visão favorável ao lazer com aventura.

Em relação aos benefícios supostos a esse tipo de esporte/lazer, as repostas mais recorrentes são: intensificação das emoções $(30,83 \%)$, qualidade de vida $(33,53 \%)$, sair da rotina $(18,26 \%)$ e rejuvenescer $(13,77)$. A respeito do suposto rejuvenescimento, observou-se que a média etária do respondente foi de 40 anos, possibilitando intervir que as práticas de aventura apresentam o estereotipo de maior vitalidade. A Juventude é o termo concebido pela Sociologia, para designar o período interstício entre funções sociais da infância e as funções sociais do adulto. Uvinha (200l) em pesquisa com skatistas de idades variáveis apresenta considerações sobre 
muitos deles acreditarem que a juventude está em como cada um se sente e pretende viver.

Ao entrevistarmos um veterano do skate, com 52 anos de idade e conhecido como "Marreta" entre os praticantes da modalidade, ele cita que, quando conheceu o skate na década de 70 , para ele "era como uma brincadeira de criança. Se podia brincar de carrinho em cima do carrinho. Começou como diversão, mas tornou-se uma profissão". $\mathrm{Na}$ etapa do campeonato de longboard na qual esse sujeito foi entrevistado, participaram 47 competidores vindos do Paraná, São Paulo e Rio Grande do Sul. A idade dos mesmos variou de 17 (mínima) a 42 (máxima), sendo 25 anos a média da faixa etária e moda de 23 anos.

Embora a maioria desses sujeitos ainda seja considerada jovem, já há tendência em se prolongar a prática para além da adolescência ou da vida universitária. Essas atividades de aventura deixam de restringir à determinada fase de vida (quando os riscos são mais tolerados) para fazerem parte do estilo de vida. Mas por que os tempos atuais privilegiam a aventura em diferentes idades?

Para Jankélévitch (1963), o aventureiro é da mesma ambigüidade que a aventura. Nada está definido na aventura nem no futuro, que é um enigma, a exemplo da data da morte. Por usar de sua liberdade para adentrar em coisas incertas e contingentes, o aventureiro está à margem da vida prosaica, vivendo uma desinência do futuro. Logo, o aventureiro oscila clandestinamente entre a busca pela estabilidade da economia diária e a sedução pelo profundo desejo em arriscar. A atualidade, marcada pela incerteza quanto aos riscos futuros, parece favorecer esse tipo aventureiro. Não obstante a disseminação desse perfil parece predominar um recorte de classe no tocante ao seu modus operandi.

\section{Mapeando a demanda}

Segundo Betrán e Betrán (1998), a partir dos últimos 20 anos as sociedades avançadas experimentam o auge de atividades de aventura no tempo livre com impactos econômicos, culturais, sociais e ambientais. Dada a possibilidade dos recursos não serem suficientes à demanda, inviabilizando um crescimento sustentável, se faz necessário identificar a demanda potencial (não-praticantes) e real (praticantes).

Em estudo desenvolvido na região da Catalunha, as aventuras mais desejadas foram: ciclismo de montanha e escalada (terra), mergulho e jet ski (água) rope swing, páraquedismo e vôo livre (ar), conforme Betrán (2003) e Betrán e Betrán (1998). As diferenças entre estudos desenvolvidos ou citados pelos autores e os resultados obtidos por este estudo podem ser ilustradas no quadro abaixo.

Quadro 1. Demanda real e potencial pelas atividades de aventura

\begin{tabular}{|l|l|l|l|}
\hline CARACTERISTICAS & Betrán; Betrán (1998) & $\begin{array}{l}\text { Centro de Investigação } \\
\text { Sociológica (CIS) e } \\
\text { Conselho Superior de } \\
\text { Desportes (CSD), } \\
\text { (1995). }\end{array}$ & $\begin{array}{c}\text { Resultados da } \\
\text { pesquisa }\end{array}$ \\
\hline ABRANGÊNCIA & Barcelona & Espanha & Maringá \\
\hline OS MAIS DESEJADOS & Mergulho e jet-ski & & Surf e rafting \\
\hline SETOR ÁGUA & $\begin{array}{l}\text { Rope swing, pára- } \\
\text { quedismo e vôo livre }\end{array}$ & $\begin{array}{l}\text { Pára-quedismo, vôo- } \\
\text { livre e balonismo }\end{array}$ \\
\hline SETOR AR & Montain bike e & $\begin{array}{l}\text { Montanhismo e } \\
\text { trekking }\end{array}$ \\
\hline SETOR TERRA & Montain bike, rafting e \\
OS MAIS PRATICADOS & $\begin{array}{l}\text { Terra 86\% (ciclismo, } \\
\text { trekking); Água 09\% } \\
\text { (rafting), Ar 04\% (vôo } \\
\text { livre) }\end{array}$ & Trekking, rapel e skate \\
\hline $\begin{array}{l}\text { IDADE MAJORITÁRIA } \\
\text { DOS PRATICANTES }\end{array}$ & 15 a 25 anos & 15 a 44 anos & 18 a 39 anos \\
\hline
\end{tabular}

Diferenças podem ser consideradas pela característica de cada região e pelo conhecimento prévio de cada grupo. Para ilustrar, enquanto Barcelona é uma cidade marítima, próxima aos Pirineus, Maringá não possui proximidade com mar ou montanha. 
Entre as atividades de aventura já praticadas, quando tomamos como $\mathrm{N}$ de amostra 207 respondentes, foram relatados trekking $(8,21 \%)$, rapel $(6,28 \%)$, skate $(5,79 \%)$, motocross $(2,89 \%)$, rafting $(2,41 \%)$ e surf $(2,41 \%)$. Interessante notar que, além de figurarem entre os mais desejados, pára-quedismo e vôo-livre estão acessíveis num raio de $100 \mathrm{~km}$ do município. Todavia, o fator de risco (tido numa primeira visão destes como alto) e o custo do curso para iniciantes ( $R \$ 450,00$ e $R \$ 600,00$, respectivamente) ou para turismo ( $R \$$ 250,00 e $R \$ 150,00$ ) podem explicar o baixo índice de praticantes tanto em Maringá como na Espanha.

A propósito, com base no Atlas do Esporte no Brasil (DA COSTA, 2005), ratifica-se a universalidade dessa afirmação, sem considerar, evidentemente, a influência da geografia sobre as oportunidades (como no caso do surf em Florianópolis - SC). No balonismo, por exemplo, há cerca de 150 praticantes no Brasil. O custo unitário aproximado de 25 a 30 mil reais e a necessidade de infra-estrutura terrestre inibem o ingresso dos novos adeptos. No pára-quedismo, há em território nacional 924 atletas registrados na confederação desse esporte, sendo que os custos podem justificar um baixo número de praticantes assíduos. O vôo-livre é praticado por cerca de 5000 pessoas; a maioria pilotando parapente. Trata-se, portanto, de grupos quantitativamente bem restritos.

As práticas que alcançaram certa disseminação estão relacionadas a baixos custos, seja pela massificação do acesso turístico ou a equipamentos. No primeiro caso encontra-se o rafting, estimando-se que 100 mil pessoas já tenham descido rios com bote, sem terem necessitado intenso treinamento prévio. Sobre as formas mais populares de acessibilidade, o skate firma-se como uma das práticas mais populares do Brasil, envolvendo uma grande massa na faixa etária de 5 à 16 anos. Estimativas do mercado registraram um contingente de 2,7 milhões de adeptos no Brasil. O mercado nacional (fábrica de peças, roupas, calçados - atacado e varejo) fatura cerca de $\mathrm{R} \$ 200.000 .000,00$. (BITENCOURT; AMORIM, 2005).

Outra atividade de grande adesão e acessibilidade nacional é o grupo de caminhadas em trilhas, incluindo o trekking. O fato de não exigir novas tecnologias e poder ser praticada por qualquer pessoa, em qualquer faixa etária, e não oferecer risco efetivo (desde que praticada com orientação) faz com que o mesmo seja considerada uma das atividades na natureza mais acessíveis e que abraça grande parte dos pacotes de ecoturismo. (BITENCOURT et al, 2005).

Por essa lógica, a acessibilidade, o menor risco e o baixo custo para a prática da caminhada em trilhas, a levam ao topo das mais praticadas neste estudo, podendo ser observada também a elevada média de idade, quase coincidindo com a média da amostra total (34 anos).

A respeito de fatores que pudessem ser associados aos esportes de maior demanda na região, ramificou-se uma rede de entrevistas com comerciantes de Maringá, onde foram indagados sobre a faixa etária de seus consumidores, mercado consumidor acima de 40 anos, produtos mais vendidos, relatos dos praticantes após iniciação das práticas e expectativas para o futuro neste mercado ainda pouco abrangente, sendo possível observar algumas características marcantes da região de acordo com o comércio:

Conforme os resultados obtidos, o perfil dos consumidores deste mercado de aventura concentra-se numa maioria dos homens entre 18 e 30 anos, pertencentes a um grupo social de classe média, preocupados principalmente com a qualidade de vida. De fato, esse é um mercado dominado por barreiras de gênero, faixa etária e condição econômica. O mercado consumidor acima de 40 anos, por exemplo, é restrito às atividades com caminhada/corrida e centra-se mais na aquisição de roupas apropriadas. A dependência relativa do modismo e a segmentação restritiva, entretanto, parecem não interessar aos comerciantes, pois isso limita a perspectiva de expansão dos negócios.

A insegurança dos comerciantes ampara-se na disparidade entre demanda potencial e real. Enquanto o interesse pela aventura engloba metade das pessoas abordadas, os percentuais daqueles que praticam ou praticaram, isto é, quem efetivamente já consumiu aventura, é de $25 \%$ dos indivíduos. Há, de fato, uma demanda reprimida. Tal grupo potencial ainda não apresentou efetividade seja por falta de tempo, ocasião, condição financeira ou outros fatores (isoladamente ou combinados). Foi significativo o não interesse $(49,27 \%)$ em praticar qualquer atividade de aventura. Essa reserva se 
manifestou particularmente entre pessoas com idade média de 28 anos (moda: 18 anos) e 73,73 $\%$ abaixo do nível superior de escolaridade.
Em relação à demanda real, o quadro abaixo apresenta o tipo de benefícios relatados, por modalidade praticada.

Quadro 2. Representações de praticantes quanto a benefícios das atividades de aventura

\begin{tabular}{|c|c|c|c|c|}
\hline & Mais saúde & Emoções fortes & Sair da rotina & Rejuvenescer \\
\hline Skate & $30,3 \%$ & $30,3 \%$ & $21,2 \%$ & \\
\hline Trekking & $27,7 \%$ & $25,5 \%$ & $21,2 \%$ & \\
\hline Rapel & $30,3 \%$ & $24,2 \%$ & $18,1 \%$ & \\
\hline $\begin{array}{c}\text { Montanhism } \\
0\end{array}$ & $33,3 \%$ & $33,3 \%$ & $16,6 \%$ & \\
\hline MotoCross & $27,7 \%$ & $22,2 \%$ & $33,3 \%$ & \\
\hline Rafting & & $28,5 \%$ & $21,4 \%$ & $18,1 \%$ \\
\hline Surf & & $36,3 \%$ & $18,1 \%$ & $18,1 \%$ \\
\hline Arvorismo & $25 \%$ & & $18,7 \%$ & $25 \%$ \\
\hline Vôo-livre & $16,6 \%$ & $16,6 \%$ & $33,3 \%$ & \\
\hline Tirolesa & $27,2 \%$ & $18,1 \%$ & $18,1 \%$ & \\
\hline
\end{tabular}

No somatório das práticas, obteve-se a seguinte ordem decrescente de benefícios: Mais saúde/qualidade de vida; Sair da rotina; Emoções fortes; Rejuvenescer/estar sempre jovem; Contato com a natureza; Motivações compensatórias; e Espiritualidade. Quando pensamos anteriormente que a relação com o ambiente natural não configura as atividades de aventura para a grande parcela das pessoas comuns do cotidiano, se vê que, para os praticantes, essa relação é tida como um ganho ou benefício. Entretanto, essa relação parece estar afetada, em boa parte, por uma dimensão hedonista (sair da rotina, ter fortes emoções) e por uma outra instrumental (saúde). Enfim, estar com a natureza é proporcionalmente pouco vista, mesmo pelos praticantes, como um bem em si.

O benefício mais lembrado foi a saúde, tendo os praticantes se referido de forma parcial (mental ou física) ou global. Aparenta ser paradoxal que as atividades de aventura, conhecidas pelo risco de acidentes, sejam vistas como promotoras de melhora na saúde ou na qualidade de vida (categorias de significados diferentes, equiparadas nas representações coletivas). Essas representações sugerem inclusive ser razoável a colocação de Amaral (2005) a respeito de um movimento mercantil no turismo de aventura, vendendo a adrenalina como uma espécie de fármaco natural.

O sucesso dessa fórmula reside na percepção de praticantes que o estresse agudo da aventura suspende temporariamente o estresse cotidiano. Esse entendimento da saúde como beneficio perde força no motocross, vôo-livre e principalmente, nas atividades aquáticas. Para rafting e surf, a intensificação das emoções, como desfrute hedonista do presente, parece bastar-se. Contudo, mais que encontrar diferenças entre os benefícios relatados, estes parecem manter uma sutil sinergia. A percepção de um pode bem implicar o outro como causalidade. 
Assim, hipoteticamente, a juventude de espírito é mantida por rupturas com a rotina, intensificando emoções, com efeitos positivos ao bem estar. Como essa relação é dialética, a ordem dos fatores não é necessariamente como foi demonstrado. O grupo apresentou-se seguindo um padrão de idade média de 26-27 anos em sua maioria, sendo observado que a idade média mais avançada (33 anos) enquadrou-se na caminhada/trekking. Para muitos, é uma aventura focada em caminhadas nos ambientes naturais, sendo considerado de menor risco e exigências físicas para sua execução, o que pode contribuir para haver uma faixa etária mais velha entre os praticantes.

Por fim, quando comparadas, as três cidades apresentam diferenças na demanda. Quanto maior o IDH maior o interesse pela prática de atividades de aventura. Quanto menor esse índice na cidade, mais singelas financeiramente são as experiências. Independente da cidade, as vivências mais onerosas (mais risco e tecnologia) ou estavam concentradas em militares ou em profissionais liberais. Assim, escolaridade e estabilidade profissional aumentam as chances de praticar uma maior diversidade de aventuras. Porém, o IDH não teve associação com o percentual geral de praticantes. Todas essas relações discutidas são boas hipóteses à medida que não trazem respostas, mas proporcionam pontos de partida para estudos aprofundados das relações insinuadas.

\section{Considerações Finais}

Diante do crescimento do mercado de atividades de aventura (na natureza ou nas cidades), buscamos entender como estão organizadas as representações sociais da demanda real e potencial pelas mesmas. Uma das expectativas seria que os respondentes apontassem a conexão do praticante em relação aos elementos da natureza, forjando uma espécie de "consciência ecológica", já que o sucesso de muitas ações depende diretamente de uma harmonia com o meio. Porém, essa relação foi pouco manifestada pelos respondentes, levando ao necessário questionamento do rótulo ecológico para as atividades de aventura.

Em análise preliminar, os resultados apontam que a compreensão firma-se, sobretudo, no reconhecimento da desigualdade de acesso à prática. Esta é justificada em termos de condição econômica, antropomórfica e disponibilidade de tempo, fatores que em si remetem ao padrão consumidor jovem burguês dessas práticas. Enfim, a maior parte da população atenta a esse fenômeno não se afasta dele por ser preconceituosa em relação ao mesmo, mas por entender não se enquadrar nas condições concretas para sua fruição.

Em complemento, a participação do poder público na organização de políticas sobre atividades de aventura é ainda tímida. O mesmo se faz presente pontualmente no apoio a eventos com esportes de aventura e na normalização e "terceirização" de espaços (como no parque nacional de Foz de Iguaçu) para o turismo de aventura. Quando se trata de democratizar o acesso a esse tipo de vivência, ainda não existe uma demanda que pressione participação estatal decisivamente. Porém, os movimentos de skatistas pela construção de rampas públicas e aqueles vindos das empresas de turismo e sociedade organizada, exigindo normalização do setor, indicam que a temática começa a deixar de ser exclusividade do círculo privado de consumidores e comerciantes do setor. O comportamento da demanda para valer seu direito às práticas de aventura e as estratégias das ofertas merecem desdobramento em futuras investigações.

Por fim, o estudo sugeriu que o entendimento de atividade de aventura está majoritariamente circunscrito ao que é institucionalizado: o turismo e, principalmente, ao esporte de aventura. Neles as sensações densas e excepcionais proporcionaram bem estar e vitalidade em situações de risco controlado. Uma vez que a Educação Física, ou a Ciência da Motricidade, com certo atraso, interessou-se pelas atividades de aventura como objetivo de pesquisa e meio de intervenção, é nessa realidade já em devir que profissionais deverão atuar (e transformar). Por outro lado, a pesquisa foi desenvolvida em local com poucas condições geográficas de desenvolvimento "espontâneo" de outras possibilidades. Em diferentes contextos é plausível encontrar novos dados e representações. Neste sentido, é recomendada a realização de estudos em outras regiões para comparações, considerando a pertinência do survey para inspirar e fornecer problemas qualitativos para estudos mais aprofundados. 


\section{Referências}

AMARAL, M. C. O desafio da aventura sport fair e o turismo de aventura. In: UVINHA, R. R. (Org.). Turismo de aventura: reflexões e tendências. São Paulo: Aleph, 2005. p.233-236.

BETRÁN, J. O. Rumo a um novo conceito de ócio ativo e turismo na Espanha: as atividades físicas de aventura na natureza In: MARINHO, A.; BRUHNS, H. T. (Orgs.). Turismo lazer e natureza. Barueri- SP: Manole, 2003, p. 182-189.

BETRÁN, A. O.; BETRÁN, J. O. análisis de la demanda potencial de las actividades físicas de aventura en la naturaleza en la ciudad de Barcelona. Apunts. Barcelona (España), n. 52, p. 92-102, 1998.

BITENCOURT. V.; AMORIM. S.; RIBEIRO. A.; KOOF. Pára-quedismo. J. In: DA: COSTA, L. (Ed.). Atlas do Esporte no Brasil. Rio de Janeiro: Shape, 2005. p. 481

BITENCOURT. V.; AMORIM. S. Skate. In: DA: COSTA, L. (Ed.). Atlas do Esporte no Brasil. Rio de Janeiro: Shape, 2005. p. 421

COSTA, V. L. M. ; MARINHO, A.; PASSOS, K. C. M. Esportes de aventura e esportes radicais: propondo conceitos. Revista Motriz, Rio Claro (SP), v.13, n. 12 (suplemento), maio/ago, p.S188, 2007.

DA COSTA, L. (Ed.). Atlas do Esporte no Brasil. Rio de Janeiro: Shape, 2005.

DIAS, C. A. G. ; ALVES JUNIOR, E. D. Entre o mar e a montanha: esporte, aventura e natureza no Rio de Janeiro. Niterói, RJ: EdUFF, 2007.

GEBARA, A. Sociologia configuracional: as emoções e o lazer. In: BRUHNS, H. T. (Org.) Lazer e ciências sociais. Campinas: Cronos, 2000. p. 75-92.

JANKÉLÉVITCH, Vladimir. L'aventure, l'ennui, lê sérieux. Paris: Aubier, 1963.

LAHIRE, B. A cultura dos indivíduos. Porto Alegre: Artmed, 2006.

MINAYO, M. C. S. O desafio do conhecimento: pesquisa qualitativa em saúde. 6. ed. São Paulo: Hucitec, 1999.

SPINK, M. J. O estudo empírico das

representações sociais. In: (Org.). $\mathrm{O}$ conhecimento no cotidiano: as representações sociais na perspectiva da psicologia social. São Paulo: Brasiliense, 1995. p. 85-108
SWARBROOKE, J.; BEARD, C.; LECKIE, S.; POMFRET, G. Turismo de Aventura: conceitos e estudos de casos. Rio de Janeiro: Elsevier, 2003.

THOMAS, J. R.; NELSON, J. K. Métodos de pesquisa em atividade física. Porto Alegre: $\mathrm{d}$. Artmed, 2002.

UVINHA, R. R. Juventude, lazer e esportes radicais. Barueri- SP: Manole, 2001.

Esse artigo foi apresentado em Sessão Temática no VI Congresso Internacional de Educação Física e Motricidade Humana e XII Simpósio Paulista de Educação Física, realizado pelo Departamento de Educação Física do IB/UNESP Rio Claro, SP de 30/4 a 03/5 de 2009.

Endereço:

Giuliano Gomes de Assis Pimentel

Av. Colombo, 5790

Campus da UEM

Maringá PR Brasil

87020-900

e-mail: ggapimentel@uem.br

Recebido em: 10 de fevereiro de 2009.

Aceito em: 03 de abril de 2009.

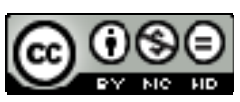

Motriz. Revista de Educação Física. UNESP, Rio Claro, SP, Brasil - elSSN: 1980-6574 - está licenciada sob Licença Creative Commons 